\title{
Ação social $e$ intersetorialidade: relato de uma experiência na interface entre saúde, educação e cultura
}

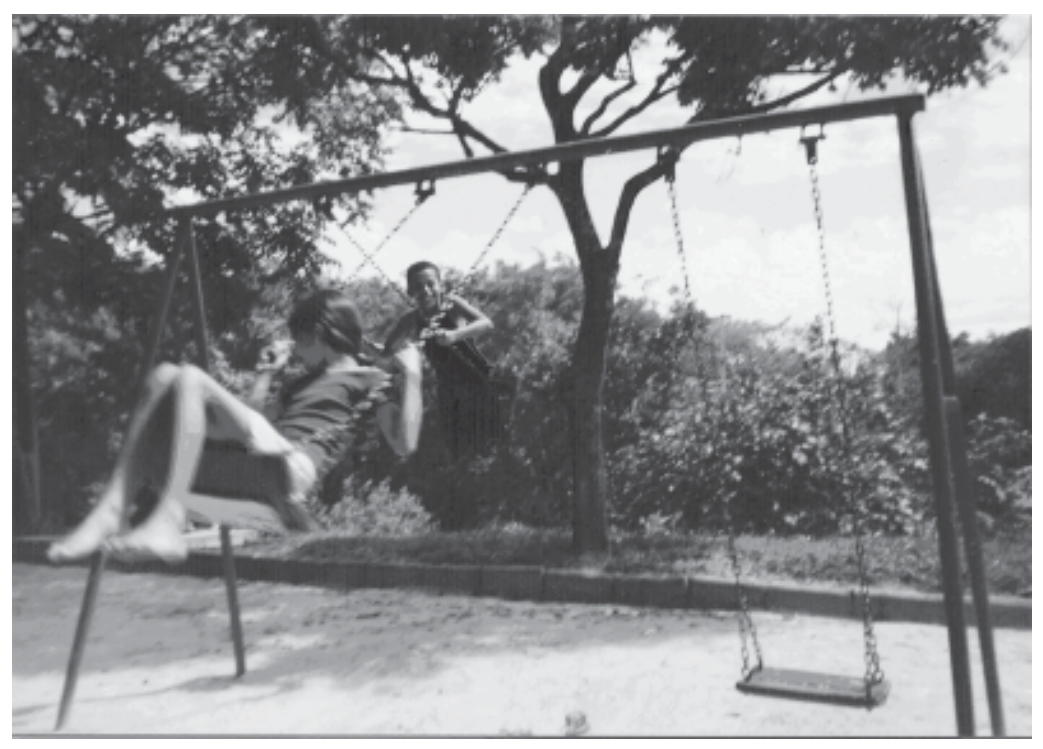

Oficina de fotografia, Núcleo UFSCar do projeto Metuia e projeto Rotas Recriadas Centro de convivência Tear das Artes, 2005

*Este trabalho teve apoio da Secretaria de Ensino Superior do Ministério da Educação, por meio do Programa de Apoio à Extensão Universitária Voltado às Políticas Públicas- PROEXT 2004 /SESu-MEC, e da Pró-Reitoria de Extensão da Universidade Federal de São Carlos (UFSCar).

${ }^{1}$ Professora adjunta, Departamento de Terapia Ocupacional e Programa de Pós-Graduação em Educação, UFSCar; coordenadora, projeto Metuia, São Carlos, SP. <relopes@power.ufscar.br>

${ }^{2}$ Terapeuta ocupacional, projeto Rotas Recriadas e projeto Metuia; professora assistente substituta, Departamento de Terapia Ocupacional, UFSCar. <amalfitano@uol.com.br> 


\section{O serviço: apresentando as rotas e seus desafios}

Apresentamos a experiência de um projeto de extensão desenvolvido por meio da parceria entre Universidade e Serviço, envolvendo a Universidade Federal de São Carlos (UFSCar) e o projeto Rotas Recriadas - Campinas/ SP ${ }^{3}$.

Esta experiência contou com financiamento do Ministério da Educação, por intermédio da Secretaria de Ensino Superior - SESu, Programa de Apoio à Extensão Universitária voltado às Políticas Públicas - PROEXT/ 2004, e da Pró-Reitoria de Extensão da UFSCar.

O projeto Rotas Recriadas: crianças e adolescentes livres da exploração sexual em Campinas- $\mathrm{SP}^{4}$ foi implementado pela Prefeitura Municipal de Campinas, em uma proposta intersetorial, que reuniu ONGs (Organizações Não-Governamentais) locais por meio do Conselho Municipal de Direitos da Criança e do Adolescente - CMDCA/ Campinas.

Esse projeto contou com um financiamento da empresa Petrobras, com recursos de isenção fiscal. A equipe da empresa Petrobras - com base no conhecimento das rotas de exploração sexual de crianças e adolescentes - convidou, em 2004, sete parceiros técnicos para o desenvolvimento de projetos de intervenção e elaboração de metodologias sociais (pesquisa-ação) de enfrentamento ao referido fenômeno. Foram eles: Manaus e Belém: Centros de Defesa; Piauí: Universidade Federal do Piauí (intervenção em quatro municípios); Aracajú: Prefeitura Municipal de Aracajú; Goiânia: Universidade Católica de Goiânia (intervenção em quatro cidades); Foz do Iguaçu: ONGs, e Campinas: Prefeitura Municipal de Campinas e Conselho Municipal de Direitos da Criança e do Adolescente (Campinas, 2004a).

A temática da violência na sociedade perpassa as esferas da cultura, do imaginário, do contexto social, incluindo a violência sexual como um de seus componentes. A violência sexual envolve uma gama de conceitos e problemáticas que são de extrema complexidade, exigindo ações articuladas, intersetoriais e interdisciplinares para seu enfrentamento. Sua compreensão deve englobar o abuso sexual intra e extrafamiliar, atentado violento ao pudor, estupro e a exploração sexual comercial (Faleiros, 2000).

\begin{abstract}
A violência sexual contra crianças e adolescentes acontece em escala mundial, esteve sempre presente em toda a história da humanidade, e em todas as classes sociais, articulada ao nível de desenvolvimento e civilizatório na sociedade em que acontece. (...) É consensual nos estudos sobre a violência sexual contra crianças e adolescentes que esta é uma relação de poder entre desiguais, exercida através da dominação e/ou da sedução. (Faleiros, 2005, p.2)
\end{abstract}

O aspecto da relação de poder abordado por Faleiros é consensual nas diversas explicações sobre o fenômeno da exploração sexual, sendo aqui entendido como o uso da criança ou do adolescente para propósitos sexuais em troca de algo (favores, dinheiro, afeto, etc.), praticado por um cliente, familiar, intermediário, agenciador ou qualquer pessoa que se beneficie dessa prática por meio de uma relação de poder (Hazeu, 1998).

A exploração sexual comercial de crianças e adolescentes desdobra-se nas modalidades atualmente evidenciadas no mundo da economia global: prostituição, turismo sexual, pornografia e tráfico para fins sexuais (Leal, 2003).

As ações desenvolvidas pelo projeto Rotas Recriadas dedicaram-se ao enfrentamento da subcategoria prostituição, evento fortemente constatado na cidade e região. Para o estabelecimento das ações, considerando as multicausalidades que envolvem a problemática da violência sexual infanto-juvenil, acredita-se ser essencial a implantação de programas intersetoriais e a construção de redes de serviços, com fluxos complementares (Vasconcelos \& Malak, 2002).

\author{
${ }^{3}$ Projeto desenvolvido \\ pelo Programa de \\ Extensão da \\ Universidade Federal \\ de São Carlos \\ (UFSCar): Metuia - \\ Terapia ocupacional no \\ campo social. O projeto \\ Metuia é um grupo \\ interinstitucional de \\ estudos, formação e \\ ações pela cidadania \\ de crianças, \\ adolescentes e adultos \\ em processos de \\ ruptura das redes \\ sociais de suporte, do \\ qual participam \\ docentes, discentes e \\ profissionais da área \\ de terapia ocupacional \\ de três universidades \\ paulistas: Pontifícia \\ Universidade Católica \\ de Campinas, \\ Universidade Federa \\ de São Carlos e \\ Universidade de São \\ Paulo (Barros et al. \\ 2002). Dedica-se à \\ realização de estudos, \\ pesquisas, formação \\ de alunos de \\ graduação e pós- \\ graduação e \\ implementação de \\ intervenções, no \\ campo social, que \\ discutam o papel \\ social dos técnicos, \\ em especial do \\ terapeuta ocupacional \\ e suas contribuições \\ no enfrentamento de \\ problemáticas \\ contemporâneas.
}

${ }^{4}$ Projeto premiado no $4^{\circ}$. Marketing Best de Responsabilidade Social, tendo sido apresentado pela empresa Petrobras, por meio de seu financiamento para implementação das ações. 
Nessa direção, o projeto Rotas integrou, para a constituição da rede, o Plano Municipal da Infância e Juventude e o Plano Municipal de Enfrentamento à Violência Sexual InfantoJuvenil (Campinas, 2003).

Buscando contemplar a interface entre os campos de atuação, no intuito de constituir uma proposta intersetorial e interdisciplinar, o projeto foi desenhado em eixos de intervenção, a saber:

- Prevenir - oferta de atividades culturais e esportivas para os adolescentes, constituindo espaços de convivência nos bairros e fomentando grupos associativos e/ou cooperativas.

- Buscar e diagnosticar - implementar um sistema de informação unificado; realizar busca ativa das crianças e adolescentes em pontos conhecidos, por meio de educadores sociais.

- Cuidar e proteger - oferta de tratamento médico, psicológico, terapêuticoocupacional, trabalho corporal, terapias complementares, prevenção DST/ AIDS, redução de danos, etc. Apoio jurídico, casa de acolhimento provisório, retorno familiar, auxílio financeiro para proteção (bolsa auxílio).

- Capacitar - capacitar profissionais participantes do projeto e da rede local de equipamentos sociais (servidores públicos e de ONGs, lideranças do bairro - adultos e adolescentes).

- Comunicar - produção de material informativo e educativo, divulgação nos meios de comunicação oficial e na mídia.

- Fiscalizar - criar uma rede de ajuda entre as instituições públicas que têm, entre suas missões, a fiscalização, como: o Conselho Tutelar, Ministério do Trabalho, Ministério Público, Vara da Infância e Juventude, Delegacia da Mulher, dentre outras.

- Gestar - acompanhamento das ações, prestação de contas, captação de financiamento. A gestão é realizada por intermédio de uma coordenação para cada eixo e de um colegiado (Campinas, 2004a).

Este trabalho se detém na discussão das ações centradas nos eixos Prevenir e Cuidar, apresentados, a seguir, com mais detalhes.

\section{Eixo Cuidar}

O eixo Cuidar foi concebido com o intuito de oferecer à população-alvo cuidados em saúde, em especial em saúde mental, para apoio, formação de vínculo e auxílio para a construção conjunta e participativa de novos projetos individuais que se traduzam na (re)criação de novas rotas e percursos em suas vidas.

Para a realização do trabalho, foram escolhidas, como estratégia de implementação, três ações: inserção de um técnico de saúde mental em cada distrito de saúde da cidade ${ }^{5}$, criação de uma equipe especial para a região central, local notoriamente reconhecido enquanto espaço de maior concentração da temática no município, e alocação de um técnico para atuar em um bairro historicamente conhecido como área de prostituição local.

A equipe do eixo Cuidar elegeu o acolhimento, a escuta qualitativa, o vínculo, a

${ }^{5}$ A divisão distrital segue os princípios do Sistema Único de Saúde - SUS, que preconiza a descentralização do atendimento à saúde, de modo que o território de Campinas encontrase subdividido em cinco regiões/distritos, com serviços de saúde circunscritos a cada um. construção de projetos de vida, a diminuição de fatores de vulnerabilidade social, e o fortalecimento da rede pessoal e significativa de suporte, como referências e instrumentais prioritários de trabalho (Campinas, 2004b).

\section{Eixo Prevenir}

O eixo Prevenir tinha a missão de implantar centros de convivência em diferentes pontos da cidade e ofertar atividades culturais e esportivas para as crianças e os adolescentes que vivem em regiões carentes de espaços de lazer e daquelas atividades, localizadas nas rotas em que existem indícios de exploração sexual. 
Tais centros de convivência compõem a estratégia que busca facilitar e/ou viabilizar o acesso a bens culturais e criar espaços de pertencimento e convivência em comunidades com poucos equipamentos sociais, objetivando promover ações de prevenção concernentes ao campo, assim como a qualificação de suas abordagens e metodologias. Pretendeu-se, também, implementar oficinas e grupos culturais que propiciassem a geração de renda, visando ao fomento de grupos associativos e/ou cooperativas, por meio da utilização de linguagens que estimulassem a participação dos jovens e o protagonismo juvenil (Projeto Rotas Recriadas, 2004b).

Os centros de convivência, na proposição do projeto Rotas Recriadas, deveriam ser eleitos como locais prioritários para a presença dos técnicos do Eixo Cuidar, pois se constituíam como espaços atribuídos à convivência, o que os caracterizava enquanto equipamento educativo e promotor de desenvolvimento psicossocial. A inserção do profissional da área de saúde no espaço da ação social, educação e cultura almejava a aproximação com os adolescentes, o levantamento de demandas, a realização de ações de mediação e de encaminhamentos para as necessidades apresentadas.

Portanto, fazia-se necessário o apoio técnico como subsídio para as ações locais, potencializando as atividades e as relações humanas enquanto meio de criação de vínculos, convivência e aprendizado, e não como fim por si só, mas, também, fundamentando a necessária conexão, para o trabalho, nesse campo, entre saúde, educação e cultura. Aposta-se na convivência e na atividade enquanto elementos-chave para a aproximação, para o vínculo e para o estabelecimento de trabalhos com adolescentes em situação de vulnerabilidade social.

\section{Oficinas de fotografia: o que há por trás das lentes?}

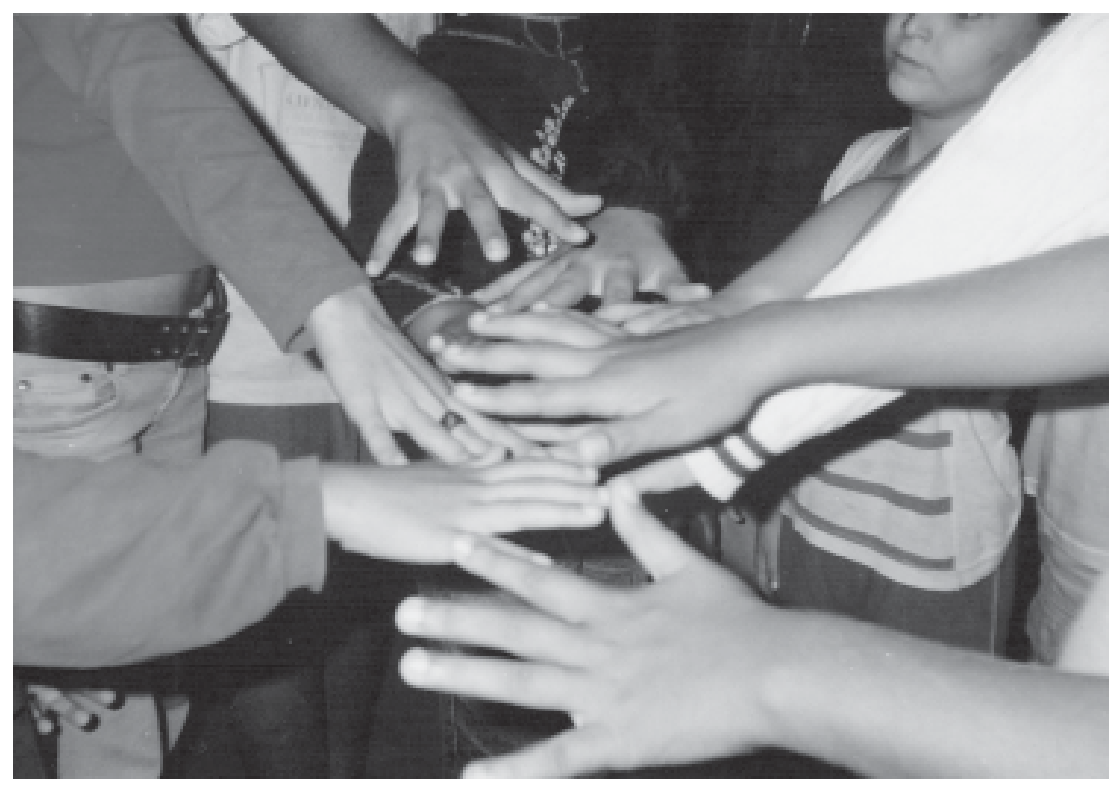

Oficina de Fotografia - Núcleo UFSCar do Projeto Metuia e Rotas Recriadas Centro de Convivência Boa Vista - 2005 


\section{A proposta}

A parceria estabelecida buscou oferecer apoio aos técnicos do projeto Rotas, discutindo a efetivação do projeto com essa população, bem como a formação de alunos de graduação e a produção e divulgação de materiais sobre o tema.

Quanto às atividades diretamente realizadas com a população-alvo do trabalho, foram feitas oficinas, com a temática da imagem - por meio da utilização da fotografia enquanto recurso, durante dois meses, em dez locais do projeto Rotas, tendo sido priorizados os centros de convivência, pelas razões anteriormente expostas. As oficinas se deram em oito centros, em um espaço comunitário ligado ao centro de saúde local e em um Centro de Atenção Psicossocial - CAPS infantil.

Para a operacionalização das oficinas, contamos com a intervenção de 16 estudantes ${ }^{6}$ de graduação da UFSCar, sendo quinze estudantes do curso de terapia ocupacional e uma do curso de psicologia. Eles eram acompanhados por profissionais dos equipamentos

${ }^{6}$ Agradecemos aos alunos Ana Dourado, Bárbara Miranda, Bruna Toledo, Bruno Maxta, Diana Garcia Diana Cavaglieri, Iara Guimarães, Letícia Matias, Lisiane M. Yonezawa, Luana Amâncio, Patrícia Bueolni, Paula Furlan, Priscila Silva, Renata Fornacierir, Sara Sfair e Wagner Oda,pela participação e contribuição significativa no projeto. sociais nos quais estavam alocados e contavam, também, com supervisão individual e coletiva.

As oficinas de fotografia trabalharam, no nível individual, com a percepção de si e de seu local de pertencimento, utilizando as fotos como recursos facilitadores, por intermédio de uma perspectiva de participação coletiva das crianças e jovens (Dale, 1999), tendo sido utilizada a presença de adultos de referência para a efetivação da proposta.

A imagem possui um potencial de significação que, muitas vezes, proporciona a aproximação com a criança e com o jovem, podendo ser utilizada enquanto um instrumento intermediário para que se favoreça a formação do vínculo, vínculo este que permite ao profissional oferecer novas possibilidades de vivências e de cotidiano para aquele que se encontra em situação de vulnerabilidade social (Lopes et al., 2002a).

A inserção de um elemento novo, como a máquina fotográfica, diferencia-se do cotidiano daquela população, atraindo sua atenção para novas ações que possam ser realizadas e fundadas nos espaços que ocupam. Para que estes aspectos sejam alcançados, ressaltamos a necessidade de se trabalhar numa perspectiva do protagonismo juvenil, que vislumbre, na criança e no jovem, o principal interventor na sua vida (Costa, 2004).

A realização das oficinas de fotografia objetivou, também, a inserção desse recurso nas ações dos profissionais locais, permitindo que se apropriassem de novas formas de linguagem e de aproximação com aquelas crianças e adolescentes.

\section{As oficinas de fotografia: outros significados}

A realização das oficinas de fotografia integrou um processo de diferentes etapas: a aproximação com aquele território e o equipamento social em questão; o conhecimento e contato com as crianças que o freqüentam; o relacionamento com o profissional de referência daquele local, enfim, a inserção dos técnicos. A partir daí, a efetivação da proposta: o início da oferta da atividade, a busca da integração em um grupo específico, a proposição e o desenvolvimento do tema da imagem e auto-imagem, o trabalho com a máquina fotográfica, a exposição dos resultados alcançados.

A opção por estar em uma diversidade de espaços propiciou-nos conhecer a multiplicidade de perfis que se aproximam de uma proposição como a deste projeto. Cada local está ligado à cultura de seu território e ao histórico de cada equipamento em sua região. Transitamos da periferia ao centro da cidade, em contato com a população infantil e juvenil, em locais como: bairros com uma rede de equipamentos sociais mais efetiva; outros com uma organização comunitária que se destaca; espaços nos quais o tráfico de drogas tem grande influência; a região central onde meninos e meninas em situação de rua são o público-alvo, dentre outras características singulares.

Estar nesses locais nos permitiu o contato com uma parte da infância e juventude da 
cidade, que se encontra em vulnerabilidade social. As vulnerabilidades são muitas, passando pela violência doméstica, negligência de cuidados, evasão escolar, falta de aportes sócio-afetivos, uso abusivo de substâncias psicoativas, pobreza extrema, entre outras. Trata-se de fatores complexos presentes na sociedade contemporânea, que se ligam, em algumas histórias de vida, à exploração sexual. Não é possível abordar a exploração sexual sem fazer uma conexão com a desigualdade social, com a violência e com fatores macroeconômicos (Leal, 2003).

Tal abordagem, porém, não pretende se traduzir em uma concepção 'medicalizante' da sociedade, na busca de "doenças sociais" ou de "indivíduos em risco". Pelo contrário, lidar com o tema em sua complexidade implica que ações de prevenção, como aquelas previstas para os centros de convivência do projeto Rotas, dediquem-se a oferecer suportes sociais para as crianças e adolescentes daquele território, por meio de ações de cultura, saúde e educação, em uma perspectiva social, que se traduzam em pertencimento e aportes.

Algumas dessas características levantadas estiveram presentes no desenvolvimento das oficinas: fazer uma maquete de bairro e relembrar de onde veio sua família; falar sobre imagem e apontar quanto é difícil reconhecer a própria imagem; fotografar o bairro e ter o desejo de denunciar suas mazelas; utilizar a máquina fotográfica e ter - pela primeira vez um retrato de seu bebê. Estes, dentre tantos exemplos, foram fragmentos que propiciaram a inserção das histórias de vida no processo das oficinas de fotografia.

Para o acolhimento dessas demandas, visualizamos a atividade enquanto instrumento intermediário e potencializador da aproximação, do vínculo e da ressignificação, a partir de novos modelos e experiências a serem vivenciados.

É de extrema relevância que essa forma de utilização da atividade, enquanto elementomeio, e não elemento-fim, ocorra junto com o arte-educador local, para que ele perceba as outras possibilidades inseridas em seu trabalho, para além da formação na oficina específica, como hip-hop, capoeira, dança, arte circense etc. O resultado concreto - aprender a técnica - é de grande valia para aqueles que possuem aquele talento específico, não devendo ser menosprezado ou não serem propiciadas novas oportunidades de desenvolvimento desse talento; porém, estar em grupo, conviver, ser acolhido, são ganhos intermediários, de extremo valor, que os centros de convivência devem estabelecer tendo, portanto, que estar no horizonte dos resultados do trabalho local, inclusive do arte-educador.

Durante o desenvolvimento das oficinas, o contato com a máquina fotográfica foi um momento de grande atração e novidade nos espaços. Como destacamos acima, trata-se de um elemento novo, curioso, interessante. As crianças e adolescentes tiraram fotos livres, para aproximação com o equipamento, e, posteriormente, temáticas, para uma exposição final do trabalho realizado. Todos puderam escolher fotos para si, levando-as para casa como um dos seus produtos.

Elemento-meio e elemento-fim estiveram presentes durante o processo. Como proposta de finalização das oficinas de imagens, realizamos uma exposição para a divulgação do material produzido pelas crianças e adolescentes participantes. O local escolhido foi a sede da Secretaria de Cultura do Município - um dos órgãos responsáveis pelos centros de convivência do projeto Rotas Recriadas, por ser uma referência cultural para a cidade, local de exposições, shows, feiras etc.

A inauguração da exposição contou com a presença dos participantes das dez oficinas realizadas, além de profissionais dos centros de convivência, funcionários do projeto Rotas Recriadas e profissionais relacionados à área da infância e adolescência no município. Para animar a festa, grupos de samba e de dança, vindos dos centros de convivência participantes das oficinas, apresentaram-se no local. Buscou-se, com esse evento, colocar em evidência o processo do trabalho realizado, pautando as crianças e adolescentes como seus autores.

Destacamos, por fim, que, por trás das lentes das câmeras fotográficas, abordamos subjetividades, singularidades, histórias, vulnerabilidades que estão presentes no cotidiano daqueles meninos e meninas. 


\section{O processo de formação de recursos humanos}

Os projetos desenvolvidos no campo social têm demandado pessoas qualificadas que se dediquem a intervenções em seu contexto. São contratados profissionais da saúde, educação, cultura, ciências humanas e sociais, dentre outros, aos quais se solicitam diferentes contribuições na composição da chamada equipe interdisciplinar.

O campo social é uma esfera de interface, apresentando uma diversidade de núcleos a serem desenvolvidos por diferentes áreas (Malfitano, 2004), fator que se almeja encontrar nos profissionais deste campo; seriam os "operadores sociais", conforme denomina Barros (1991).

Porém, a formação de grande parte dos profissionais não prevê suportes para a atuação enquanto "operadores" do campo social e encontra-se, na absoluta maioria das vezes, calcada em apenas um aspecto de intervenção, não se direcionando para a dimensão territorial, da convivência, da superação da clínica e da manutenção das singularidades de cada história.

Estes fatores eram vivenciados cotidianamente no projeto Rotas Recriadas.

Dentro deste contexto - por meio do desenvolvimento desta proposta - foi uma das intenções da Universidade a viabilização da formação de estudantes de graduação naquilo que se direcione para a sua sensibilização para intervir com um outro olhar no campo social, com ações voltadas ao território, reconhecendo a funcionalidade e a relevância da atuação na promoção de redes de suporte locais para a população infantojuvenil.

Trata-se, ainda, de pautar essa importante problemática do território nacional, a exploração sexual de crianças e adolescentes, enquanto preocupação dos técnicos, que devem buscar contribuir para criar caminhos alternativos para um quadro sabidamente complexo, implementando práticas sociais que produzam resultados efetivos na diminuição das vulnerabilidades às quais estão expostas nossas crianças e adolescentes.

Propomos o debate sobre o projeto pedagógico para a formação de novos profissionais, vislumbrando a formulação de uma prática interdisciplinar e intersetorial, que valorize e estabeleça a conexão entre saúde, cultura e educação; profissionais esses que se dediquem ao enfrentamento das grandes situações de vulnerabilidades vivenciadas pela infância e juventude brasileiras.

\section{Projetos no campo social: qual proposição de sustentabilidade?}

A experiência aqui relatada refere-se a uma proposta realizada por uma parceria entre a Universidade e o projeto em desenvolvimento. Nesse processo, contudo, integrávamos também a equipe de implantação do projeto e vivenciamos diferentes fases do curso da proposta.

O trabalho com a população infanto-juvenil em situação de exploração sexual tem sido apontado como prioritário por diferentes instâncias do governo (Miranda, 2005), sendo que, no nível federal, tem havido diversos incentivos para intervenções, pesquisas e publicações em torno dessa temática.

Observa-se, contudo, que grande parte das ações desenvolvidas é de responsabilidade de ONGs em parceria com o Estado, que realizam projetos pontuais aos quais não é garantida a sua continuidade em virtude, sobretudo, da questão do financiamento dos mesmos. Isso acaba por ocasionar uma pontualidade e transitoriedade das experiências que não chegam a se consolidar, produzindo impactos bastante restritos em relação às problemáticas para as quais direcionam sua atenção.

Esta é uma realidade da maioria dos projetos sociais no Brasil atualmente. $\mathrm{O}$ advento do "terceiro setor" - privado, porém público, na expressão de Fernandes (1994) - tem 
propiciado a retirada do Estado enquanto provedor de ações e serviços sociais (Montaño, 2002), colocando-o como parceiro da sociedade civil para o oferecimento de serviços à população.

Esses aspectos estiveram presentes no projeto Rotas Recriadas.

A metodologia proposta para o trabalho, dividida em eixos de intervenção, apresentou-se, nos nove meses de implantação, adequada para abordagem com aquela população. Contudo, apontou necessidades de ajustes, aperfeiçoamentos e adequações, que não se relacionavam, porém, em nossa opinião, com a necessidade de mudança no desenho metodológico em andamento.

É relevante destacar que o aspecto mais desafiador, verificado também na experiência aqui apresentada, diz respeito à concretização da intersetorialidade nas práticas das ações, na integração entre os eixos de intervenção - sendo que nosso trabalho buscou, com muito empenho, concretizar essa interface entre o cuidar e o prevenir - e na efetivação de um compartilhamento de saberes, com horizontalidade e integração de diferentes profissionais e ações, para o qual as relações hierarquizadas e de poder em nada contribuem.

Contudo, o projeto Rotas Recriadas enfrentou enormes dificuldades em relação à sua continuidade, e que passaram pela questão da redução do financiamento, pelo fato de estar em um momento de mudança de gestão municipal, pela dificuldade de diálogo e debate dos técnicos e da direção do projeto com o Conselho Municipal de Direitos da Criança e do Adolescente, dentre outros, que refletiam claramente a realidade vivenciada por ações dessa natureza e sua fragilidade de sustentação.

Cabe questionarmos o que significa a priorização nacional em torno da criança e do adolescente, segundo o ECA - Estatuto da Criança e do Adolescente, e as diretrizes criadas para o enfrentamento de suas demandas, como, por exemplo, a problemática da exploração sexual infanto-juvenil. Qual a possibilidade de real impacto em tão complexa problemática, se a maioria das propostas em andamento no país restringe-se a projetos-parceriastransitórios?

Neste ponto, vale destacar a relevância da função social desempenhada por esses projetos, especialmente no campo da produção de subjetividades mais fortalecidas diante da vulnerabilidade; contudo, sua fragilidade e pequena incorporação pela esfera pública, fundamentalmente enquanto política pública que lide com os direitos decorrentes da cidadania e que, portanto, devem atendê-los, produzi-los e ampliá-los, limitam fortemente a possibilidade de resultados efetivos, e a maioria deles propicia "apenas" resultados pontuais.

O projeto Rotas Recriadas, após ficar, aproximadamente, cinco meses sem implementar suas ações, retornou ao cenário da cidade com uma mudança de desenho metodológico e com propósitos diferenciados em algumas das ações desenvolvidas.

Após uma série de debates, optou-se pela gestão do projeto por meio da centralização da intervenção em três ONGs do município, ficando a maior parte das ações sob a responsabilidade e gerência de uma delas: o CRAMI - Centro Regional de Atenção aos Maus-Tratos na Infância - Campinas. Esse encaminhamento provocou um esvaziamento e a finalização das ações desenvolvidas nos equipamentos sociais públicos até então utilizados, como os centros de saúde e centros de convivência, tornando prioritária a realização do trabalho por meio das ONGs. Ainda, tal direcionamento cessou o investimento que vinha sendo feito no fomento de discussões sobre o fenômeno da exploração sexual no âmbito das unidades de saúde, das escolas, dos centros de convivência, dentre outros equipamentos sociais públicos nos quais, raramente, tal assunto é tratado.

Também, como conseqüência desse reordenamento do projeto, destacamos a retirada da busca concreta da ação intersetorial do seu cotidiano. O desafio de tecer a conjunção entre saúde, educação e cultura, visando à criação de estratégias para a aproximação e trabalho com a criança e o adolescente, deixa de ser prioridade em prol do desenvolvimento de intervenções locais e individualizadas. 
Consideramos que a complexidade de projetos dessa natureza demanda uma maior incorporação por parte do Estado, nos diferentes níveis de gestão e instituições, bem como um lugar de efetiva prioridade para que se possa, a partir de uma sustentabilidade mínima enraizada, lançar-se ao desafio da mudança de rotas de vidas de muitas de nossas crianças e adolescentes.

\section{Considerações finais}

O projeto Rotas Recriadas, no enfrentamento da temática da exploração sexual no município de Campinas, almejava a constituição de uma prática intersetorial de ações, da prevenção ao cuidado, que envolvessem propostas do campo da educação, cultura, saúde, justiça, trabalho e assistência social, compondo a rede de serviços sociais para a população infantojuvenil.

No âmbito das ações direcionadas às crianças e aos adolescentes, compartilhamos do ideal e da dificuldade da implantação de ações intersetoriais e interdisciplinares, que reconheçam o campo social em sua complexidade e estabeleçam os elos e os trânsitos necessários entre as diferentes áreas.

Acreditamos que a perspectiva da promoção dos direitos, estabelecida pelo ECA (Brasil, 1990), deve ser o elemento norteador dos projetos dedicados a essa população. O ECA preconiza, em seu artigo $5^{\circ}$ :

Nenhuma criança ou adolescente será objeto de qualquer forma de negligência, discriminação, exploração, violência, crueldade e opressão, punindo na forma da lei qualquer atentado, por ação ou omissão, aos seus direitos fundamentais.

É com base nesse referencial que elegemos o trabalho territorial desenvolvido nos centros de convivência como o objeto de nosso foco. A intervenção no território - propiciando o acolhimento, a escuta e o encaminhamento para as diferentes demandas das crianças e adolescentes - é uma tecnologia possível que permite a tessitura, com fios e pontos mais firmes, de redes pessoais e sociais de suporte (Lopes et al., 2002).

Para tanto, utilizamos, nesta experiência, a atividade, sob a forma de oficinas de imagem, como o elemento-meio para o desenvolvimento de tais princípios. E verificamos o potencial do recurso da fotografia como componente facilitador do trabalho.

Destacamos, ainda, a necessária formação de recursos humanos voltados a intervenções territoriais, à promoção da convivência e ao estabelecimento de equipamentos sociais que tenham a pertença e o suporte como estratégias e resultados.

Por fim, ressaltamos a viabilidade e adequação de propostas que dêem enfrentamento ao desafio da constituição de projetos intersetoriais e interdisciplinares, traçando elos conectivos entre as áreas, almejando um campo mais efetivo técnica e politicamente, onde saúde, educação e cultura se entrecruzem e se conectem, somando esforços para a diminuição das vulnerabilidades, e onde se criem e se fortaleçam as redes sociais de suportes para a infância e juventude.

\section{Referências}

BARROS, D. D.; LOPES, R. E.; GALHEIGO, S. M. Projeto Metuia - terapia ocupacional no campo social. 0 Mundo da Saúde, v.26, n.3, p.365-9, 2002.

BARROS, D. D. Operadores de saúde na área social. Rev. Ter. Ocup. USP, v.1, n.1, p.11-6, 1991.

BRASIL. Estatuto da criança e do adolescente. São Paulo: Cortez, 1990.

CAMPINAS. Secretaria Municipal de Saúde. Projeto Rotas Recriadas: crianças e adolescentes livres da 
exploração sexual. Cartilha de divulgação. Campinas: Conselho Municipal de Direitos da Criança e do Adolescente, Prefeitura Municipal de Campinas, Laboratório Cisco, 2004a. (mimeogr.).

CAMPINAS. Secretaria Municipal de Saúde. $3^{\circ}$. Relatório técnico. Campinas: Conselho Municipal de Direitos da Criança e do Adolescente, Prefeitura Municipal de Campinas, 2004b. (mimeogr.).

CAMPINAS. Câmara Municipal de Campinas. Plano municipal de enfrentamento da violência sexual infanto-juvenil. Campinas, 2003. (mimeogr.).

COSTA, A. C. G. O adolescente enquanto protagonista. Disponível em: <http://www.adolec.br/bvs/ adolec/P/cadernos/capitulo/cap07/cap07.htm>. Acesso em: set. 2004.

DALE, R. A. Participación infanto-juvenil: un reto social. El Salvador: OPS/OMS, 1999. Disponível em: <http://www2.ops.org.sv/adolec/tc/participacion_social.htm>. Acesso em: mar. 2005.

FALEIROS, E. T. S. Exploração sexual comercial de crianças e adolescentes. Disponível em: <http:// www.violenciasexual.org.br/textos/PDF/exploracao_sexual_eva_faleiros.pdf>. Acesso em: mai. 2005.

FALEIROS, E. T. S. Repensando os conceitos de violência, abuso e exploração sexual de crianças e de adolescentes. Brasília: CECRIA/MJ-SEDH-DCA/FBB /UNICEF, 2000.

FERNANDES, R.C. Privado, porém público: o terceiro setor na América Latina. Rio de Janeiro : RelumeDumará, 1994.

HAZEU, M. Exploração sexual de crianças e adolescentes: o comércio. Belém, 1998. (mimeogr.).

LEAL, M. L. P. Globalização e exploração sexual comercial de crianças e adolescentes. Rio de Janeiro: Save the Children, 2003.

LOPES, R. E.; BARROS, D. D.; MALFITANO, A. P. S.; GALVANI, D.; BARROS, G. O vídeo como elemento comunicativo no trabalho comunitário. Cad. Ter. Ocup. UFSCar, v.10, n.1, p.61-72, 2002a.

LOPES, R. E.; BARROS, D. D.; MALFITANO, A. P.; GALVANI, D. Histórias de vida: a ampliação de redes sociais de suporte de crianças em uma experiência de trabalho comunitário. O Mundo da Saúde, v.26, n.3, p.426-34, 2002b.

MALFITANO, A. P. S. Políticas públicas e movimentos sociais: atenção à infância e o Programa de Saúde da Família. 2004. Dissertação (Mestrado) - Faculdade de Educação, Universidade Estadual de Campinas, Campinas.

MIRANDA, N. Motorista cidadão em defesa das crianças e adolescentes. Rev. CNT, fev. 2005. Disponível em: <http://www.cnt.org.br/cnt/comunicacao_revistacnt_fevereiro_2005_opiniao.asp>. Acesso em: 18 mai. 2005.

MONTAÑO, C. Terceiro setor e questão social: crítica ao padrão emergente de intervenção social. São Paulo: Cortez, 2002.

VASCONCELOS, M. G. O. M.; MALLAK, L. S. (Orgs.). Compreendendo a violência sexual em uma perspectiva multidisciplinar. Carapicuíba: Fundação Orsa Criança e Vida, 2002. 
Trata-se da análise de uma experiência desenvolvida junto ao Projeto Rotas Recriadas, em Campinas - SP, que se dedicou a constituir formas de enfrentamento à violência sexual infantojuvenil, em especial à exploração sexual. Com base em uma parceria com o Núcleo UFSCar Universidade Federal de São Carlos - do Projeto Metuia, foram realizadas atividades de extensão, formação acadêmica e desenvolvimento de pesquisas. Trabalhou-se com oficinas de atividades, tendo a imagem, individual e coletiva, como elemento catalisador da possibilidade de ressignificação pessoal, em dez Centros de Convivência. Buscou-se, nessa perspectiva, a inserção do profissional de saúde no espaço da ação social, educação e cultura, para: a aproximação com os adolescentes, levantamento de demandas, realização de ações de mediação e de encaminhamentos para as necessidades apresentadas. Discute-se a convivência e a atividade enquanto elementos-chave para a aproximação, para o vínculo e para o estabelecimento de trabalhos com adolescentes em situação de vulnerabilidade social.

PALAVRAS-CHAVE: adolescente. parcerias em saúde. vulnerabilidade social. pesquisa interdisciplinar. violência sexual. serviço social.

Social programs and intersectionality: reporting an experience where health, education and culture cross lines

This paper is an analysis of an experience developed along with the Projeto Rotas Recriadas, in Campinas (state of São Paulo), a project designed to combat child and teenager sexual abuse, and in specific sexual exploitation. Through the partnership with Projeto Metuia, promoted by the Federal University of São Carlos, participants carried out academic and research activities. Workshop activities were developed, using individual and collective images as elements to assist in reestablishment of self, at ten Social Centers. In this project health professionals were introduced in a social, educational and cultural sphere, seeking to reach the teenagers, identify their demands and promote actions aiming to mediate and address the specific needs identified. The paper discuss the need for social interaction and activities as key elements in the process of bonding, creating ties and establishing goals for teenagers who are socially vulnerable.

KEY WORDS: adolescent. health consortia. social vulnerability. interdisciplinary research. sexual violence. social works.

Acción social e intersectorialidad: historia de una experiencia en la interfaz entre salud, educación y cultura

Este trabajo es un análisis de una experiencia desarrollada junto al Proyecto Rutas Recreadas, en Campinas - SP, el cual se ha dedicado a constituir maneras de enfrentar la violencia sexual infanto-juvenil, más especialmente la explotación sexual. Por medio de un convenio con el Núcleo UFSCar - Universidade Federal de São Carlos - del Proyecto Metuia, se han realizado actividades de extensión, formación académica -y desarrollo de investigación. Han sido realizados talleres de actividades, utilizando la imagen, individual y colectiva, como elemento catalizador de la posibilidad de resignificación personal, en diez Centros de Convivencia. Se ha buscado la inserción del profesional de salud en el espacio de la acción social, educación y cultura, para la aproximación a los adolescentes, relevamiento de demandas, realización de aciones de mediación y de encaminamientos de las necesidades presentadas. Se discute la convivencia y la actividad como elementos clave para la aproximación, para el vínculo y para la realización de trabajos con adolescentes en situación de vulnerabilidad social.

PALABRAS CLAVE: acolescente. consorcios de salud. vulnerabilidad social. investigación interdisciplinaria. violencia sexual. servicio social. 


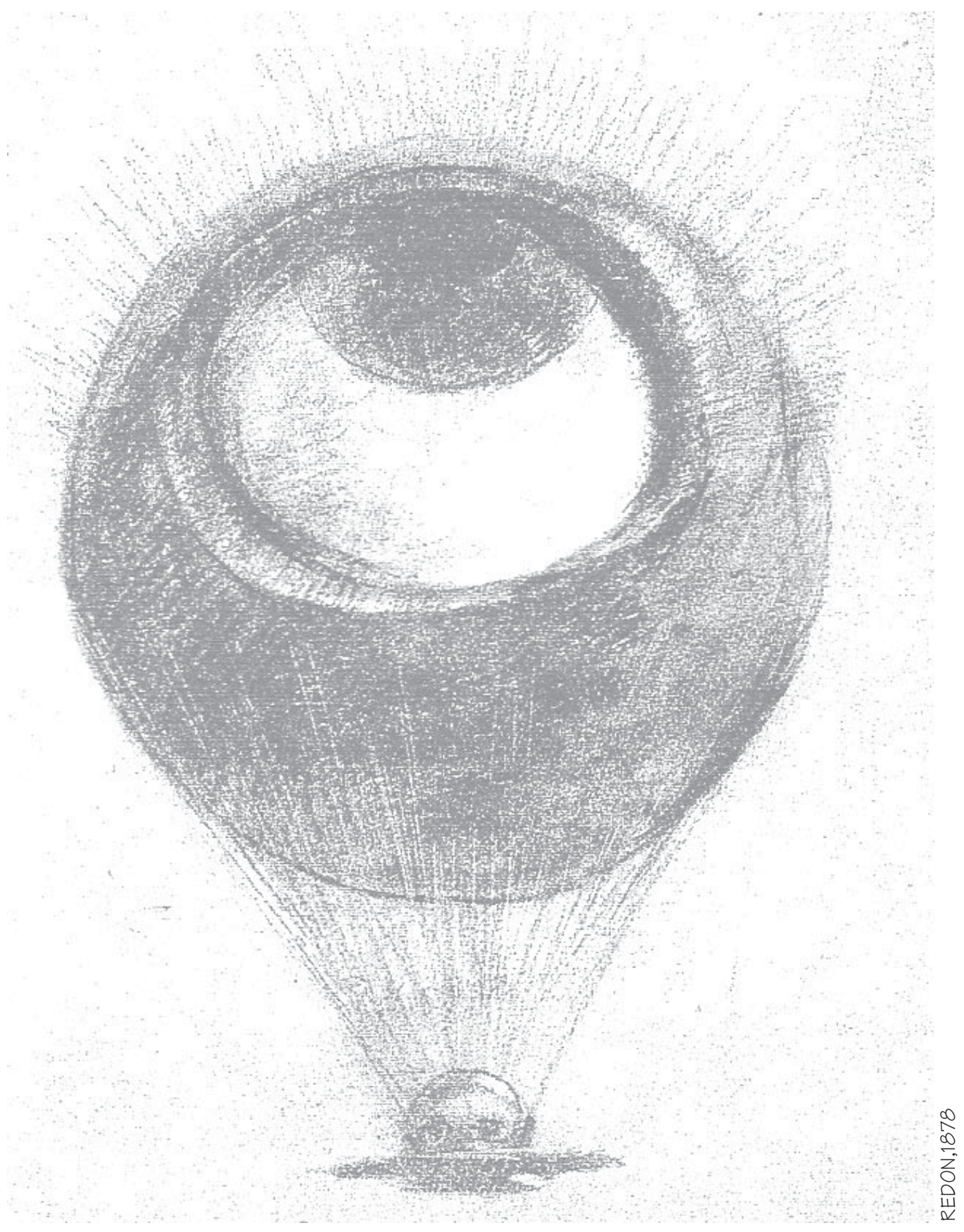

